\title{
Metal ions in drug design, neuroscience and disease
}

\section{P051}

Studies on new platinums and synergism from drug combination as applied to ovarian cancer cell lines Fazlul Huq ${ }^{1}$, Philip Beale ${ }^{2}$, Jun Q Yu ${ }^{1}$

${ }^{1}$ Discipline of Biomedical Science, University of Sydney, Sydney, Australia. ${ }^{2}$ Sydney Cancer Centre, Sydney, NSW, Australia. F.Huq@usyd.edu.au

Considerable research effort has been directed at rule-breaker platinums with the idea that the difference in nature of binding with DNA would translate into significant change in the spectrum of activity. We have synthesized a number of mononuclear trans-planaramine platinums of the forms: trans- $\left[\mathrm{Pt}\left(\mathrm{NH}_{3}\right) \mathrm{LCl}_{2}\right]$ and trans- $\left[\mathrm{PtLL}^{\prime} \mathrm{Cl}_{2}\right.$ where $\mathrm{L}$ and $\mathrm{L}^{\prime}$ stand for a planaramine ligand. One complex code named YH12 is found to be significantly more active than cisplatin against ovarian $\mathrm{A} 2780^{\mathrm{cisR}}$ cancer cell line. It has a resistance factor of 0.5 indicating much greater activity in the resistant cell line. A number of highly active tri-nuclear complexes have also been synthesized. We have also carried out studies on synergism between platinum drugs and that with plant compounds epigallocatechin-3-gallate (EGCG), curcumin (Cur), chlorophyllin (CHL) and paclitaxel (Tax) in ovarian cancer cell lines. The results show that designed compounds produce both sequence- and dose-dependent synergism in activity with cisplatin and plant compounds in ovarian cancer cell lines. This presentation will review the work done in our laboratory with special emphasis on rule-breaker platinums.

\section{P052}

Synergistic interaction between cisplatin and curcumin or epigallocatechin-3-gallate in killing ovarian cancer cells Nurhanan M Yunos ${ }^{1}$, Fazlul Huq ${ }^{1}$, Philip Beale ${ }^{2}$, Jun Q. Yu ${ }^{1}$ ${ }^{1}$ Discipline of Biomedical Science, Faculty of Medicine,

The University of Sydney, Lidcombe, Sydney, NSW 2141, Australia. ${ }^{2}$ Sydney Cancer Centre, Concord Hospital, Sydney, NSW 2139, Australia.nyun5669@mail.usyd.edu.au

Although cisplatin (Cis) is a widely used anticancer drug, it is known to cause severe side effects. Also, treatment with cisplatin is often associated with resistance. Many cancer patients use natural products as adjunct therapy, but little scientific data are available on the effect of the combination. This study aims to investigate the effect of combining chemotherapy with natural products such as curcumin (Cur) and epigallocatechin-3-gallate (EGCG) that are the major compounds present in turmeric (Curcuma longa) and green tea (Camellia sinensis), respectively. The drugs were added in binary combinations with Cis (Cis-Cur or Cis-EGCG) to A2780 and $\mathrm{A} 2780^{\mathrm{cisR}}$ cell lines, using five different time frames $(0 / 0,4 / 0,0 / 4,24 /$ 0 and $0 / 24 \mathrm{~h}$ ). The combination index (CI) was used to assess the nature of interaction of the drugs: CI value of $<1,=1$ and $>1$ indicated, respectively, synergism, additiveness or antagonism. Addition of cisplatin first before Cur or EGCG (0/4 or 0/24 h) was the most effective regimen in both A2780 and A2780 ${ }^{\text {cisR }}$ cell lines. The Pt-
DNA binding levels were higher when cells were treated with CisCur $(0 / 4 \mathrm{~h})$ or Cis-EGCG $(0 / 4 \mathrm{~h})$ as compared to that from Cis alone.

\section{P053}

Chiral discrimination in anticancer platinum drugs: relations to oxaliplatin toxicity in tumor cells Viktor Brabec $^{1,2}$, Jaroslav Malina ${ }^{1}$, Jana Kasparkova ${ }^{1,2}$, Giovanni Natile ${ }^{3}$

${ }^{1}$ Institute of Biophysics, Academy of Sciences of the Czech Republic, 61265 Brno, Czech Republic.

${ }^{2}$ Laboratory of Biophysics, Department of Experimental Physics, Faculty of Sciences, Palacky University, 77146 Olomouc, Czech Republic.

${ }^{3}$ Department of Pharmaceutical Chemistry, University of Bari, 70125 Bari, Italy. brabec@ibp.cz

Platinum complexes are effective anticancer drug widely used in the treatment of several human carcinomas. While the anionic leaving ligands of these drugs are likely to play a role in the transport of the complex throughout the living organism, the non-exchangeable amine ligands play an important role in the drug-DNA adduct formation and associated stereochemistry. Interaction with DNA and formation of crosslinks is considered to be the crucial step in the antitumor activity of this class of metallodrugs. Since double-helical DNA has a chiral structure, interaction with enantiomeric platinum complexes should lead to diastereomeric adducts. It has been demonstrated $[1,2]$ that DNA crosslinks of platinum complexes with enantiomeric amine ligands not only can exhibit different conformational features, but also can be processed differently by the cellular machinery as a consequence of these conformational differences. These results expand the general knowledge of how the stereochemistry of the carrier amine ligands of antitumor platinum compounds can influence some crucial processes underlying their toxicity toward cancer cells and can provide a rational basis for the design of new platinum antitumor drugs.

\section{References}

1. Malina J, Novakova O, Vojtiskova M, Natile G, Brabec V (2007) Biophys J 93:3950-3962

2. Kasparkova J, Vojtiskova M, Natile G, Brabec GV (2008) Chem Eur J 14:1330-1341

\section{P054}

Non-covalent interaction type anticancer $\mathbf{P t}(\mathrm{II})$ and Pd(II)complexes

Akira Odani $^{1}$, Hiroshi Takayama ${ }^{2}$, Mami Takemori ${ }^{1}$

${ }^{1}$ Institute of Medical, Pharmaceutical and Health Sciences,

Kanazawa University, Kanazawa 920-1192, Japan.

${ }^{2}$ Department of Chemistry, Graduate School of Science,

Nagoya University, Nagoya 464-8602, Japan.

odani@p.kanazawa-u.ac.jp

Cisplatin, clinically used anticancer Pt(II) complex, has been believed to attack DNA to form Pt-N7(Guanine) coordination and Pt-G bond is 
protected from DNA repair enzyme by the aromatic ring stacking between $\mathrm{G}(\mathrm{Pt}-\mathrm{G})$ and Phe in Pt-DNA-HMG protein adduct [1]. 4N coordinated $\mathrm{Pt}(\mathrm{II})$ and $\mathrm{Pd}(\mathrm{II})$ complexes $\mathrm{M}(\mathrm{Ar})(\mathrm{AtCn})$ involving with metal coordinated aromatic imine (Ar) and anthracene ring (AtCn), which could not coordinate DNA, showed good in vitro cytotoxicity for human cancer cell and should interact with biological targets through non-covalent interactions.

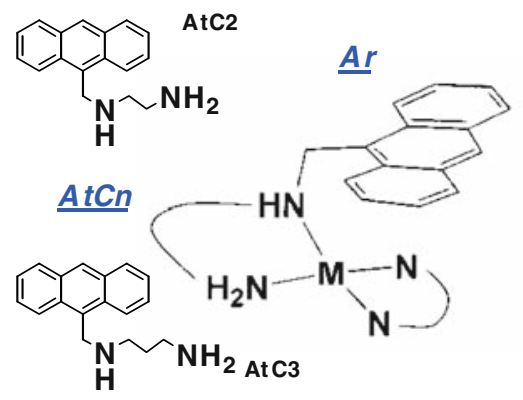

In vitro $\mathrm{IC}_{50}$ values in human cancer cell lines for $\mathrm{M}(\mathrm{Ar})(\mathrm{AtCn})(\mathrm{Ar}$ : bpy, phen derivative, pyridine, imidazole, etc., AtCn : AtC2, AtC3) were ranged between $2 \mu \mathrm{M}(\mathrm{Pd}(\mathrm{bpy})(\mathrm{AtC} 3))$ and $100 \mu \mathrm{M}(\mathrm{Pt}(\mathrm{am}-$ py)(AtC2)). Importantly the $\mathrm{Pd}(\mathrm{II})$ complex showed similar bioactivity in the corresponding Pt(II) complex.

The bioactivity indicated the structural dependence of both $\mathrm{Ar}$ and AtCn. This should be related with the intramolecular aromatic ringstacking interaction between metal coordinated pyridine or imidazole in Ar and anthracene in AtCn evidenced by the X-ray structure in crystal and the $\mathrm{H}-1$ NMR in $\mathrm{H}_{2} \mathrm{O}$ solution. The non-covalent interaction with DNA for these complexes showed various structural dependences, especially in the range of $[\mathrm{Pt}] /[\mathrm{DNA}($ base $)]>2$. The interaction with the protein such as the proteasome was also observed. These showed the stacking structure is important for the good anticancer effect in the Pt(II) and Pd(II) complexes.

\section{Reference}

1. Lippard SJ et al. (1999) Nature 399:708-712

\section{P055}

\section{Cytotoxic transition-metal semicarbazones of salicylaldehyde}

\section{J. M. Ho, K. Koh, P. Lee, Y. K. Yan}

Natural Science and Science Education, National Institute

of Education, Nanyang Technological University, 1 Nanyang Walk, Singapore 637616, Singapore. peter.lee@nie.edu.sg

Semicarbazones and their derivatives represent a versatile class of compounds which exhibit a wide spectrum of biological activities [1]. In particular, these compounds show promising activity against numerous cancer cell-lines [2]. More recently, studies have revealed that coordination of these compounds to metal ions leads to enhanced activity compared to free ligands [1]. This poster presents the synthesis, physicochemical characterization and cytotoxicity of salicylaldehyde semicarbazones and their rhenium(I) carbonyl complexes. It is envisaged that the results of this work should lead to a better understanding of the structure-activity relationship of these compounds and contribute toward rational drug design.<smiles>[R]N([R2])C(=O)N/N=C/c1ccccc1O</smiles>

Salicylaldehyde semicarbazone (R1, R2 = H, alkyl or aryl groups)

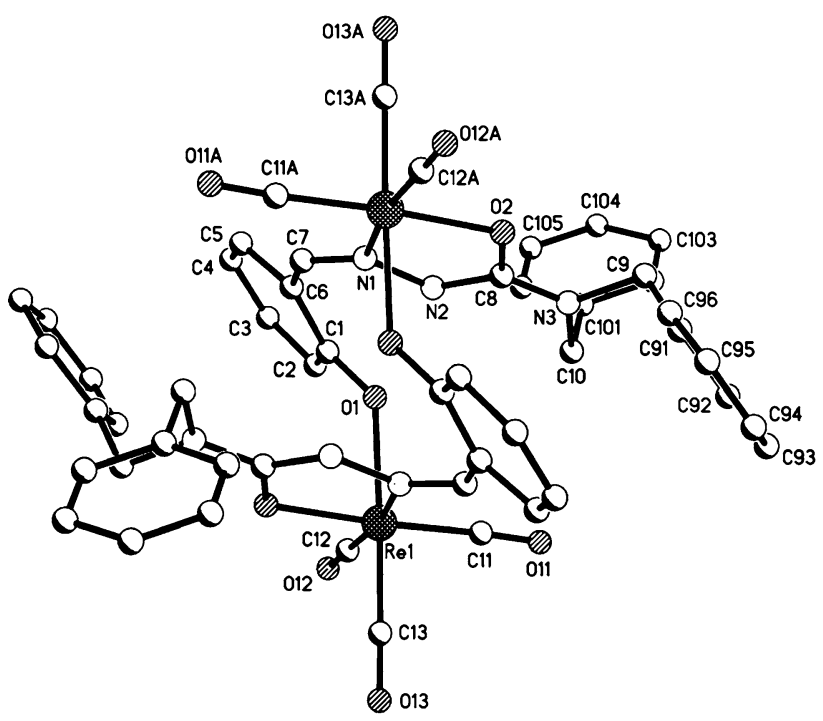

References

1. Beraldo H, Gambino D (2004) Mini Rev Med Chem 4:31

2. Quiroga AG, Ranninger CN (2004) Coord Chem Rev 248:119 (2004)

\section{P056}

Novel analytical approaches in anticancer metallodrug research

Michael Groessl $^{1}$, Christian G. Hartinger ${ }^{2}$, Bernhard K. Keppler ${ }^{2}$, Paul J. Dyson ${ }^{1}$

${ }^{1}$ Institute of Chemical Sciences and Engineering, EPFL, Lausanne, Switzerland.

${ }^{2}$ Institute of Inorganic Chemistry, University of Vienna, Vienna, Austria.michael.groessl@epfl.ch

By the hyphenation of powerful separation methods such as capillary electrophoresis or multidimensional liquid chromatography to elemental and ultra-high resolution mass spectrometers such as ICP-MS and FT-ICR-MS, new insights not only into the mode of action of already established, but also novel metal-based anticancer drugs can be gained. The techniques allow highly sensitive investigations on the stability of the complexes under physiological conditions (important for pharmaceutical preparations), their interactions with DNA as well as human serum and cellular proteins in vitro and in vivo, requiring only minute sample amounts. It is expected that implementation of the proposed techniques at an early stage of the drug development process can greatly improve its efficiency. 


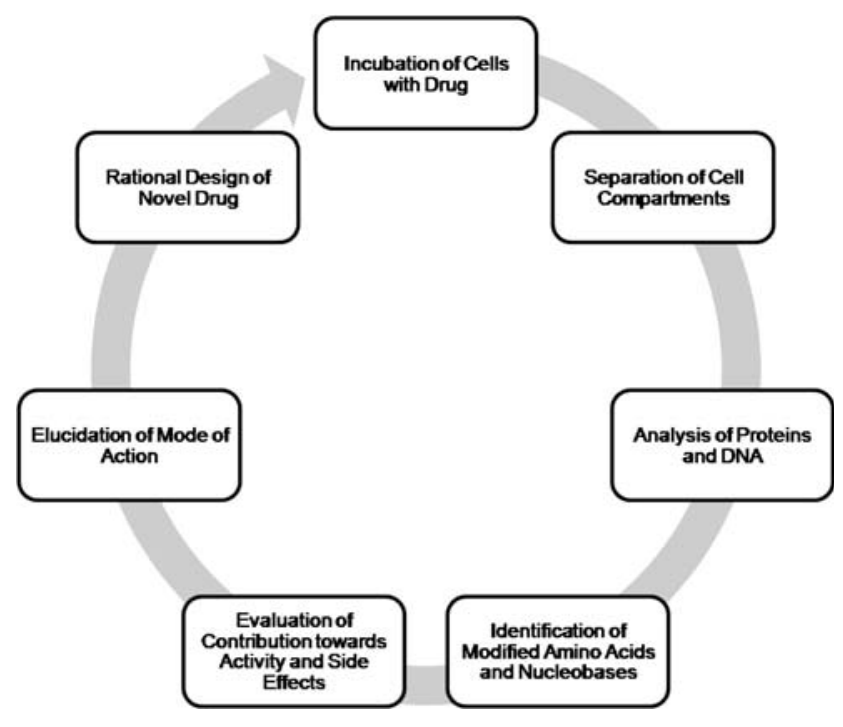

P057

Investigations into electrochemical properties of platinum(IV) agents

Xiao Gui, Hoi-Shan Chow, Trevor Hambley

School of Chemistry, University of Sydney, Sydney, NSW, Australia. t.hambley@chem.usyd.edu.au

Platinum(IV) anticancer agents has become one of the most widely researched areas in platinum chemotherapy in recent years, mainly due to their capabilities of acting as prodrugs (Fig. 1) [1]. It has been previously reported that their reduction potentials correlate with their biological activities [2]. Therefore, it is important to determine the reduction potentials of newly synthesised platinum(IV) agents as this can provide insights into their in vitro and in vivo behaviors. Two aspects of the electrochemistry of platinum(IV) agents were investigated: the dependency of their reduction on $\mathrm{pH}$ and their thermodynamic reduction potentials. In order to investigate the $\mathrm{pH}$ dependency of the reduction profiles of platinum(IV) agents, they were collected with $\mathrm{pH}$ adjusted in the range between 2 and 10. The results from this study suggest that $\mathrm{pH}$ sensitive axial groups may cause platinum(IV) agents to behave differently at different ambient pHs. The "thermodynamic" reduction potentials of some platinum(IV) complexes were also determined by varying the scan rate and extrapolate the reduction potential at scan rate of $0 \mathrm{mV} / \mathrm{s}$ (Fig. 2) [3]. The obtained reduction potential is believed to be a closer mimic to the biological reduction environment, and therefore, more biologically relevant. This study provides better insights into the reduction behavior of platinum(IV) agents in biological contexts.<smiles>[R][P+]([X])([R])N</smiles>

Inactive

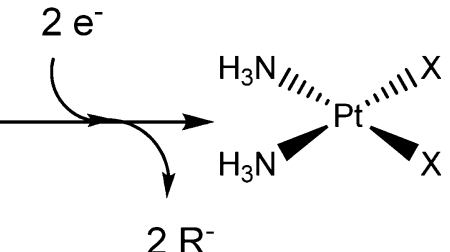

Active

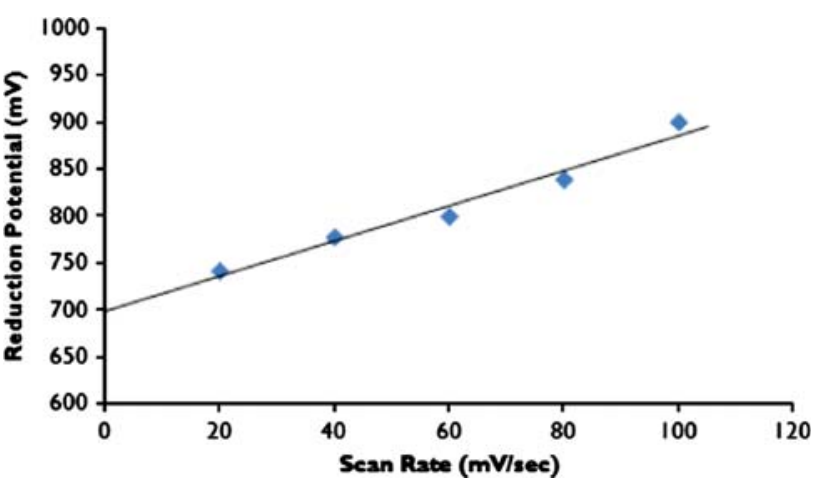

Fig. 2

References

1. Hall MD, Mellor HR, Callaghan R, Hambley TW (2007) J Med Chem 50:3403-3411

2. Ellis LT, Er HM, Hambley TW (1995) Aust J Chem 48:793-806 3. Mukhopadhyay S, Barnes CM, Hasakel A, Short SM, Barnes KR, Lippard S (2008) J Bioconjug Chem 19:39-49

\section{P058}

Multiple comparisons between dinuclear platinum(II) complexes and cisplatin in cytostatic behavior against human ovarian cancer cells

Miaoxin Lin, Xiaoyong Wang, Jianhui Zhu, Damin Fan, Zijian Guo*

State Key Laboratory of Coordination Chemistry, Nanjing University, 210093 Nanjing, People's Republic of China. zguo@nju.edu.cn Multinuclear platinum complexes constitute a novel class of prospective anticancer agents. The cytotoxicity and cytostatic mechanism of dinuclear $\mathrm{Pt}(\mathrm{II})$ complexes $\left\{\left[\text { cis- } \mathrm{Pt}\left(\mathrm{NH}_{3}\right)_{2} \mathrm{Cl}\right]_{2}\left(\alpha, \alpha^{\prime}\right.\right.$-diamino- $p$ xylene) $\}\left(\mathrm{NO}_{3}\right)_{2} \quad$ (1) and $\left\{\left[\text { cis- } \mathrm{Pt}\left(\mathrm{NH}_{3}\right)_{2} \mathrm{Cl}\right]_{2}\left(4,4^{\prime}\right.\right.$-methylenedianiline) $\}\left(\mathrm{NO}_{3}\right)_{2}(2)$ are investigated accordingly against human ovarian cancer $\mathrm{COC} 1$ cells with cisplatin as a reference. The $\mathrm{IC}_{50}$ values of 1 and $2(48 \mathrm{~h})$ are 34 and 7 times less than that of cisplatin, respectively. The apoptosis induced by $\mathbf{1}$ and $\mathbf{2}$ are more conspicuous than that by cisplatin $\mathbf{1}$ and $\mathbf{2}$ induce cell cycle arrest in G2/M phase at 1 and $10 \mu \mathrm{M}$, respectively, while cisplatin induces less specific arrest in G0/G1 and G2/M phases at $10 \mu \mathrm{M}$. The cellular Pt uptake of $\mathbf{1}$ and $\mathbf{2}$ is similar but much higher than that of cisplatin. The influence on the mitochondrial membrane potential $\left(\Delta \Psi_{\mathrm{m}}\right)$ of the cells follows an order of $\mathbf{1}>\mathbf{2}>$ cisplatin. These results demonstrate that $\mathbf{1}$ and $\mathbf{2}$ are superior to cisplatin in many respects. The differences may result from the synergism of two Pt centers in $\mathbf{1}$ and $\mathbf{2}$ and the dissimilarity

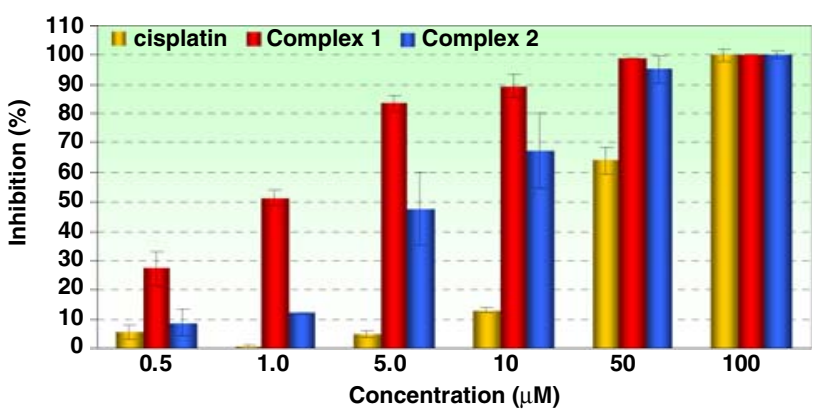

Fig. 1 The cytotoxicity of $\mathbf{1}, \mathbf{2}$ and cisplatin against COC1 cells after $48 \mathrm{~h}$ measured by the MTT assay

Fig. 1 
in DNA binding mode among these complexes. Flexibility of the linkers also plays a role in the process (Fig. 1).

\section{Reference}

1. Fan DM, Yang XL, Wang XY et al. (2007) J Biol Inorg Chem $12: 655-665$

\section{P059}

\section{Non-classical platinum complexes with anti-tumor activity: trans-platinum thiolato complexes with phosphaadamantane ligands} Fabian Mohr ${ }^{1}$

${ }^{1}$ Fachbereich C, Anorganische Chemie, Bergische Universität Wuppertal, 42119 Wuppertal, Germany.fmohr@uni-wuppertal.de Platinum complexes, in particular cisplatin cis- $\left[\mathrm{PtCl}_{2}\left(\mathrm{NH}_{3}\right)_{2}\right]$, have been in clinical use for the treatment of various cancers for more than 30 years. Despite the great success of cisplatin there is still much room for improvement. Although cisplatin is effective against a broad range of tumor types, the severe side effects and its poor solubility combined with development of cell resistance are significant disadvantages of the drug. We have, therefore, investigated platinum complexes containing the water-soluble phosphine ligand 1,3,5triaza-7-phosphaadamantane (PTA) and its $\mathrm{SO}_{2}$ derivative 2-thia1,3,5-triaza-7-phosphaadamantane-2,2-dioxide (TPADO). We have prepared complexes of the type trans- $\left[\mathrm{Pt}\left(\mathrm{SR}_{2}\right)(\mathrm{P})_{2}\right](\mathrm{SR}=$ thiolato ligand, $\mathrm{P}=$ phosphaadamantane derivative) (Scheme 1).<smiles>ClP(Cl)(Cl)(C12CN3CN(CN(C3)C1)C2)C12CN3CN(CN(C3)C1)C2</smiles>

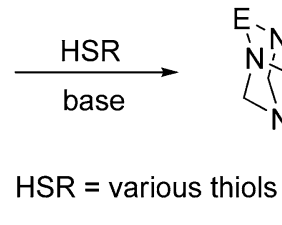<smiles>[R]SN1CN2CN(C1)CP([P+]1(S[R])CN3CNN(C3)C1)C2</smiles>

$$
\mathrm{E}=\mathrm{CH}_{2}, \mathrm{SO}_{2}
$$

\section{Scheme 1}

Although these complexes do not follow the classical mantra of antitumor active platinum complexes i.e. cis geometry and only nitrogen and chloride ligands, they exhibit in vitro cytotoxicity similar to that of cisplatin in a variety of human cancer cell lines.

\section{References}

1. Dolfen D, Schottler K, Seied-Mojtaba V, Jakupec MA, Keppler BK, Tiekink ERT, Mohr F (2008) J Inorg Biochem 102:2067-2071

2. Miranda S, Vergara E, Mohr F, de Vos D, Cerrada E, Mendía A, Laguna M (2008) Inorg Chem 47:5641-5648

\section{P060}

\section{$\mathrm{Cu}(\mathrm{II})$ Ion Inhibits early stages of amyloid $\boldsymbol{\beta}$ fibril} formation in vitro

Satoshi Fujii ${ }^{1,2}$, Ken-ichiro Yagi, ${ }^{3}$ Daisuke Miyoshi ${ }^{1,2}$, Hiroshi Sakai ${ }^{3}$, Naoki Sugimoto ${ }^{1,2}$

${ }^{1}$ Department of Nanobiochemistry, Fac. Frontiers of Innovative Research in Science and Technology (FIRST).

${ }^{2}$ Frontier Institute for Biomolecular Engineering Research (FIBER), Konan University, 7-1-20 Minatojima-minamicho, Chuo-ku, Kobe, Hyogo 658-0047, Japan. ${ }^{3}$ Department of Chemistry, Faculty of Science and Technology, Konan University, 8-9-1 Okamoto, Higashinada-ku, Kobe, Hyogo 658-8501, Japan.

satoshif@konan-u.ac.jp

Amyloid $\beta$-peptide $(\mathrm{A} \beta)$ is an essentially soluble peptide in biological fluids, but it accumulates as the main constituent of the amyloid deposits that are a principal pathological hallmark of Alzheimer's disease. Transition metal ions such as $\mathrm{Cu}$ and $\mathrm{Zn}$ have been suggested to play pivotal roles in $\mathrm{A} \beta$ aggregation in vivo. It is generally accepted that $\mathrm{Zn}$ (II) accelerates the $\mathrm{A} \beta$ fibril formation. In contrast, the effect of $\mathrm{Cu}$ (II) on $\mathrm{A} \beta$ fibril formation is somewhat complicated. Both acceleration and inhibition effects have been reported. Our previous study demonstrated that $\mathrm{Cu}(\mathrm{II})$ inhibits the fibril formation of A $\beta 42$ in vitro [1].

To elucidate the role of $\mathrm{Cu}(\mathrm{II})$ in further details, we investigated the $\mathrm{Cu}$ (II) effects on $\mathrm{A} \beta 40$ fibril formation by thioflavin $\mathrm{T}$ fluorescence, EPR, and CD spectroscopies and transmission electron microscopy (TEM). The EPR spectra showed that $\mathrm{Cu}(\mathrm{II})$ ion binds to $\mathrm{A} \beta 40$ within 30 min after mixing. $\mathrm{CD}$, fluorescence, and TEM studies indicate that this early binding of $\mathrm{Cu}$ (II) inhibits the formation of $\beta$ sheet structure and affects the morphology of $\mathrm{A} \beta$ aggregates (Fig. 1).
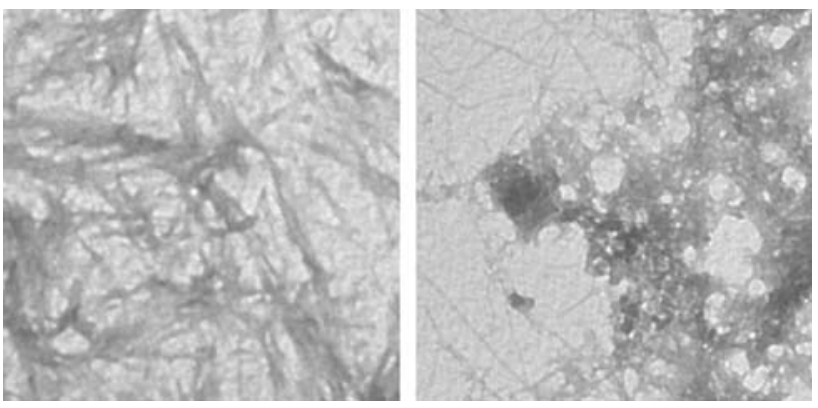

Fig. 1 TEM images of A $\beta 40$ aggregates formed after 4 days incubation in the absence of $\mathrm{Cu}$ (II) (left) and in the presence of $\mathrm{Cu}$ (II) (right)

\section{References}

1. Zou J, Kajita K, Sugimoto N (2001) Angew Chem Int Ed 40:22742277

\section{P061}

Gadolinium chloride $\left(\mathrm{GdCl}_{3}\right)$ attenuates excitotoxicity induced by NMDA in rat cortical neurons via endoplasmic reticulum stress Qing Xia ${ }^{1}$, Xudong Feng ${ }^{1}$, Hongbin Han ${ }^{2}$, Xiaoda Yang', Kui Wang ${ }^{1}$

${ }^{1}$ Department of Chemical Biology, School of Pharmaceutical Sciences, Peking University Health Science Center, Beijing, People's Republic of China. ${ }^{2}$ Radiology Department, Peking University the 3rd Hospital, 100191 Beijing,

People's Republic of China. xyang@bjmu.edu.cn

Gadolinium-based MRI agents are thought to be safe in clinical use, the in vivo release of free inorganic gadolinium $\left(\mathrm{Gd}^{3+}\right)$ has been reported recently as a potential causer of nervous system disorders. Gadolinium and other lanthanides are commonly used blockers of non-selective cation channels and other $\mathrm{Ca}^{2+}$ permeable channels. In central nervous system, ER stress plays an important role in excitotoxicity induced neurological disorders. The disruption of $\mathrm{Ca}^{2+}$ homeostasis and hypoxia can result in perturbation of ER functions or loss of integrity of the ER and then leads to unfolded protein response. In the present study, we evaluated the effects of gadolinium chloride on excitotoxicity induced by NMDA in cortical neurons via endoplasmic reticulum stress. Primary cultures of cortical neurons were prepared, and cell viability was tested by MTT. ER stress related proteins and genes were detected by western blot and RT-PCR. In the same time, intracellular $\mathrm{Ca}^{2+}$ content and reactive oxygen species 
(ROS) level were observed under a Laser scanning confocal microscope. Our results indicated that there was no obvious change of cell viability and cell mitochondrial potential was observed. Gadolinium chloride $(2 \mu \mathrm{mol} / \mathrm{L})$ obviously decreased the intracellular $\mathrm{Ca}^{2+}$ level and the expression of GRP78/Bip, Chop/Gadd153 and ATF6, but defeated to reduce the intracellular ROS increased by NMDA. In conclusion, the effects of gadolinium chloride on excitotoxity induced up-regulate of ER stress and disturb of $\mathrm{Ca}^{2+}$ signaling may be important to understand the process of neurological disorders, such as cerebral ischemia, which lead to excitotoxic state and cell death.

\section{P062}

\section{$\left([9]\right.$ aneS $\left._{3}\right) \mathbf{R h}^{\text {III }}$ Complexes containing polypyridyl ligands: DNA binding, SAR, photonuclease and antitumor activity \\ Ruth Bieda $^{1}$, William S. Sheldrick ${ }^{1}$}

${ }^{1}$ Lehrstuhl für Analytische Chemie, Ruhr-Universität Bochum, Universitätsstraße 150, 44780 Bochum, Germany.

Ruth.Bieda@ruhr-uni-bochum.de

Transition metal complexes containing polypyridyl ligands are well known for their DNA binding properties and cytotoxic activity [1]. We have initiated a systematic study of $\mathrm{Rh}^{\mathrm{III}}$ complexes of the type fac- $\left[\mathrm{RhCl}(\mathrm{pp})(\text { coligand) }]^{2+}\right.$ with facial coligands such as the tridentate macrocycle 1,4,7-trithiacyclononane and polypyridyl ligands ( $p p=b p y, b p m$, phen, tap, dpq, dppz) of different size and number of nitrogen atoms.

Interactions of the cytotoxic polypyridyl complexes with DNA were investigated by $\mathrm{CD}$ and UV/vis spectroscopy and by gel electrophoresis. In addition, ${ }^{31} \mathrm{P}-\mathrm{NMR}$ and ${ }^{1} \mathrm{H}-\mathrm{NMR}$ kinetic studies have been employed to model the reactivity of the complexes with DNA and Scontaining biomolecules. $\mathrm{IC}_{50}$ values based on crystal violet assay toward the cancer cells MCF-7 and HT-29 as well as toward the human embryonic kidney cells HEK293 were performed. Specific cell death apoptosis via DNA fragmentation was detected for BJAB cells and significant loss of the mitochondrial membrane potential in lymphoma cells indicates that the intrinsic pathway is involved.
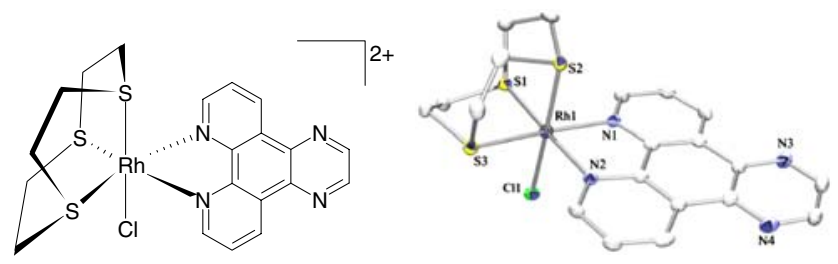

\section{Reference}

1. Harlos M, Ott I, Gust R, Alborzinia H, Wölfl S, Kromm A, Sheldrick WS (2008) J Med Chem 51:3924-3933

\section{P063}

The mechanisms of actions of gadolinium chloride $\left(\mathrm{GdCl}_{3}\right)$ on neurons

Xudong Feng ${ }^{1}$, Qing Xia ${ }^{1}$, Huixue Liu ${ }^{1}$, Hongbing Han ${ }^{2}$, Xiaoda Yang ${ }^{1}$, Kui Wang ${ }^{1}$

${ }^{1}$ State Key Laboratories of Natural and Biomimetic Drugs, Department of Chemical Biology, School of Pharmaceutical Sciences, Peking University, 100191 Beijing, People's Republic of China.

${ }^{2}$ Radiology Department, Peking University the 3rd Hospital, 100191 Beijing, People's Republic of China.xyang@bjmu.edu.cn

With medicial application of Lanthanide compounds (e.g. $\mathrm{Gd}^{3+}$ chelates as contrast agents for medical magnetic resonance imaging (MRI), lanthanum carbonate for the treatment of hyperphosphatemia of chronic renal failure (CRF) and gadolinium texaphyrin complex in phase III clinical trials for the treatment of brain metastases of nonsmall-cell lung cancer), there raised great concerns on the toxicity/ side effects of lanthanide compounds, e.g. nephrogenic systemic fibrosis (NSF) and potential neural toxicity. In the present work, we observed the effects of injection of $\mathrm{GdCl}_{3}$ into rat brain right globus pallidus and molecular mechanisms of $\mathrm{GdCl}_{3}$ on cultural rat neurons. The experimental data revealed: (1) the large dose $(0.2 \mu \mathrm{mol})$ of $\mathrm{GdCl}_{3}$ resulted in significant damage of brain tissue observed by histological analysis while the small dose $(0.02 \mu \mathrm{mol})$ did not show obvious influences on brain tissues; (2) $0.02 \mu \mathrm{mol}$ of $\mathrm{GdCl}_{3}$ caused elevated expression of endoplasmic reticulum (ER) stress chaperone Grp78 while $0.2 \mu \mathrm{mol}$ of $\mathrm{GdCl}_{3}$ resulted in significant increase of CHOP/Gadd153 expression relating to the death of brain cells; (3) in cultural rat neuronal cells, $2 \sim 20 \mu \mathrm{mol} / \mathrm{L}$ of $\mathrm{GdCl}_{3}$ resulted in decrease of intracellular $\mathrm{Ca}^{2+}$ concentration, elevation of ROS levels, up-regulating the levels of Grp78 and Chop and down-regulating elF2 phosphorylation. All these results suggest that $\mathrm{GdCl}_{3}$ could cause neuron damage by inducing ER stress associated with ROS generation. The chemistry how $\mathrm{GdCl}_{3}$ induce ROS and initiate ER stress response is being carried out in our labs.

Acknowledgements: This work was supported by NSFC (\#20671008 \& \#20637010).

\section{P064}

Mechanistic insights of anticancer metallodrugs Angela Casini ${ }^{1}$, Anastasia De Luca ${ }^{2}$, Mario Lo Bello ${ }^{2}$, Luigi Messori ${ }^{3}$, Paul J. Dyson ${ }^{1}$

${ }^{1}$ Institute of Chemical Sciences and Engineering, EPFL, Lausanne, Switzerland. ${ }^{2}$ Department of Biology, Università di Roma "Tor Vergata", Rome, Italy. ${ }^{3}$ Department of Chemistry,

University of Florence, Florence, Italy. angela.casini@epfl.ch

Since DNA is commonly believed to be the primary target of a number of metallodrugs attention has focused on the investigation of metallodrug-nucleic acid adducts, while their reactions with proteins have received, so far, much less attention. However, protein-bound metal fragments probably represent the active anticancer species rather than drug inactivation products. Also, the fact that metallation of specific side chains might affect the activity of biologically crucial 
proteins or enzymes, through formation of coordination bonds, might have an impact on the overall mechanism and toxicity of metallodrugs. Given the intrinsic complexity of these systems, appropriate and adequate investigational models and tools are needed in order to clarify the nature of the metal-protein interactions, to identify the protein bound metallo-fragments, to assess the selectivity of binding, to describe kinetics, to monitor the transfer of metallo fragments among distinct interaction sites.

Within this frame we have recently developed experimental procedures for the study of the interactions between metal complexes with model or target proteins. In particular high-resolution ESI mass spectrometry (MS) analysis turned out to provide useful information. We present here our recent results concerning the chemical characterization of the reactions between selected proteins mixtures with platinum or ruthenium complexes, obtained through this advanced approach.

\section{P065}

\section{Metalloproteomics of polypyridyl ruthenium complexes explored by LC-nanospray-MS}

Kuo-Lung Ku, Ming-Yi Ho, Kuo-Kai Liao, Chien-Chung Cheng Department of Applied Chemistry, National Chia-Yi University, Chia-Yi City 60004, Taiwan. klku@ mail.ncyu.edu.tw

Proteomic study of metal complexes in the structure-reactivity relationship provides a skylight in the development of metallopharmaceuticals. Ruthenium complexes have great potential in cancer chemotherapy due to the low toxicity and good selectivity for tumor metastasis. The reactivity of ruthenium complexes is relative to the coordinate ligands. Monochlororuthenium complexes, $\mathrm{Ru}$ (terpy) $(\mathrm{NN}) \mathrm{Cl}^{+}(\mathrm{NN}$, bidentate nitrogen ligand) were used to examine the structure-reactivity relationship in the bacterial growth. Preliminarily, the incorporation of the ruthenium complexes into part of the proteins has been confirmed by two-dimensional gel electrophoresis and ICP emission spectroscopy. Hence, we are intensively interested in that if any specific binding domains in proteins for the complexes are present. An approach of LC-nanospray-MS was used to examine the suggested binding sites in Ru-adduct peptides. The structurereactivity relationship with different ruthenium complexes will be addressed in this presentation. These results may provide a close look based on view of metallo-drugs discovery to understand the relationship between ligand effects of ruthenium complexes and binding sites of proteins, which in tune will influence the reactivity of the bacterial growth.

\section{P066}

\section{DNA-binding ability and cross-linking patterns} of dinuclear platinum(II) Antitumor complexes Jianhui Zhu' ${ }^{1}$, Miaoxin Lin ${ }^{1}$, Damin Fan', Yi Lu ${ }^{2}$ and Zijian Guo ${ }^{*, 1}$

${ }^{1}$ State Key Laboratory of Coordination Chemistry, School of Chemistry and Chemical Engineering, Nanjing University, 210093 Nanjing, China. ${ }^{2}$ Department of Chemistry,

University of Illinois at Urbana-Champaign, Urbana, IL 61801, USA. zguo@nju.edu.cn

Multinuclear platinum (II) complexes offer bright prospects for platinum-based chemotherapy, exhibiting great potentials to circumvent both intrinsic and acquired resistance to cisplatin [1]. The anticancer activity which derives from formation of novel long-range inter- and intra-strand cross-linked DNA adducts are different from those of cisplatin and analogues [2]. Our previously study found that the highly water-soluble dinuclear $\mathrm{Pt}(\mathrm{II})$ complex, $\{[$ cis$\left.\left.\operatorname{Pt}\left(\mathrm{NH}_{3}\right)_{2} \mathrm{Cl}\right]_{2} \mathrm{~L} 1\right\}\left(\mathrm{NO}_{3}\right)_{2}\left(\mathbf{1}, \mathrm{L} 1=4,4^{\prime}\right.$-methylenedianiline $)$ exhibited more potent cytotoxicity against P-388 and A-549 cell lines than cisplatin [3]. In this work, we compared the DNA binding ability and cross-linking patterns with its an analogue, $\left\{\left[\text { cis- } \mathrm{Pt}\left(\mathrm{NH}_{3}\right)_{2} \mathrm{Cl}\right]_{2} \mathrm{~L} 2\right\}$ $\left(\mathrm{NO}_{3}\right)_{2}\left(2, \mathrm{~L} 2=\alpha, \alpha^{\prime}\right.$-diamino-p-xylene $)$. The role of the bridging ligands in tuning DNA binding ability and cytotoxicity will be discussed. The result should be useful for future rational design of multinuclear Pt(II) antitumor agents.

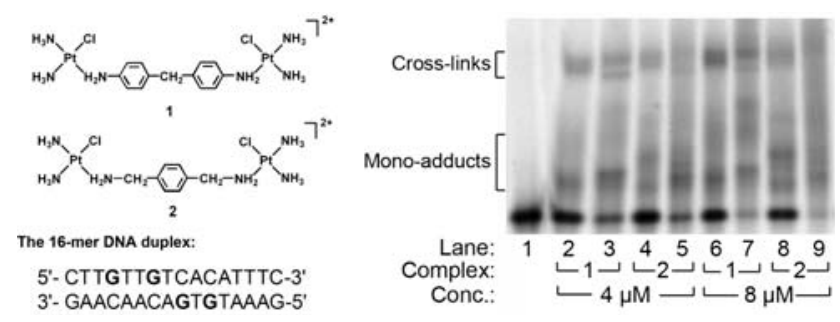

\section{References}

1. Wheate NJ, Collins JG (2003) Coord Chem Rev 241:133-145

2. Hegmans A, Berners-Price SJ, Davies MS, Thomas DS, Humphreys AS, Farrell N (2004) J Am Chem Soc 126:2166-2180

3. Fan D, Yang X, Guo Z (2007) J Biol Inorg Chem 12:655-665

\section{P067}

Preparation of metal complexes of $\mathrm{N}_{2} \mathrm{~S}_{2}$ or $\mathrm{N}_{2} \mathrm{O}_{2}$ donor set similar to the active site structure of nitrile hydratase and the reactivity for NO molecule Tatsuya Suwabe, Takuma Yano, Tomohiko Inomata, Yasuhiro Funahashi, Tomohiro Ozawa, Hideki Masuda Department of Frontier Materials, Nagoya Institute of Technology, Nagoya 466-8555, Gokiso-cho Showa-ku, Japan.

chw13333@stn.nitech.ac.jp

Nitric oxide (NO) molecule has been known as an essential element for supporting life. Once the concentration decreases in blood, arteriosclerosis develops because it is an endotherial-dependent relaxation factor. This further worsen the activity of NO synthase. Thus, direct measurement of the NO concentration from the endothelial cell has been required in order to understand the relationship between the endothelial dysfunction and functional disorder in blood vessel. Detection of NO using electrode modified with function materials such as metalloporphyrin has been tried and succeeded by following the oxidation current of $\mathrm{NO}$. However, it also interacts with $\mathrm{NO}_{2}^{-}$ion, which interferes to detect $\mathrm{NO}$ molecule.

An Fe-type nitrie hydratase interacts with a nitric oxide (NO) in the resting state. The metal center was surrounded by four negatively charged atoms, which will make the Lewis acidity of metal center decrease. We thought lowering the Lewis acidity selectively interacted with NO molecule because the reactivity of mono-radical is rather high. Therefore, we prepared $\mathrm{Co}$ (III) or $\mathrm{Fe}$ (III) complexes with $\mathrm{N}_{2} \mathrm{~S}_{2}$ or $\mathrm{N}_{2} \mathrm{O}_{2}$ donor set (Fig. 1). We will discuss on the preparation of the metal complexes and the reactivity with $\mathrm{NO}$ molecule. 


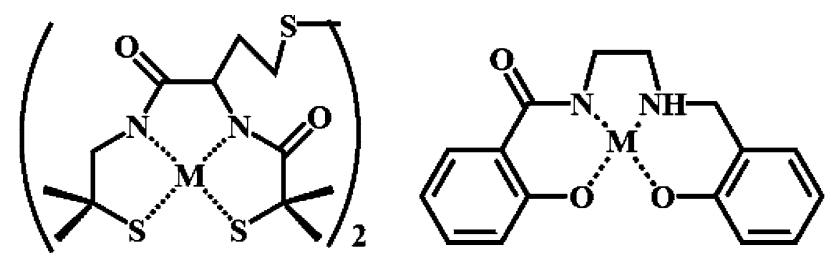

Fig. 1 Schematic structures of metal complexes used in this study (M : $\mathrm{Co}(\mathrm{III})$ and $\mathrm{Fe}(\mathrm{III})$ )

\section{P068}

Detection of apoptotic cells by means of fluorescent $\mathrm{Zn}^{2+}$ probes

Ari Iseki ${ }^{1}$, Yoshiyuki Kageyama ${ }^{1}$, Akinori Morita ${ }^{2}$, Masanori Kitamura $^{1}$, Masahiko Ikekita ${ }^{2}$, Shin Aoki ${ }^{1}$

${ }^{1}$ Faculty of Pharmaceutical Sciences, Tokyo University of Science, Noda 278-8510, Japan.

${ }^{2}$ Faculty of Pharmaceutical Sciences, Tokyo University of Science, Noda 278-8510, Japan. shinaoki@rs.noda.tus.ac.jp

The zinc ion $\left(\mathrm{Zn}^{2+}\right)$ is recognized as one of important cofactors in the regulation of apoptosis $[1,2]$. Because $\mathrm{Zn}^{2+}$ is spectroscopically silent due to its $\mathrm{d}^{10}$ electron configuration, the fluorescence $\mathrm{Zn}^{2+}$ sensors would be useful to examine the distribution and roles of $\mathrm{Zn}^{2+}$ in the apoptotic cell.

To date, several cyclen-based fluorescence $\mathrm{Zn}^{2+}$ probes have been developed (cyclen $=1,4,7,10$-tetraazacyclododecane) $[3,4,5,6,7]$ and the staining of early stage apoptotic cells was reported $[8,9]$. In this presentation, the results of the dual stain of early stage apoptotic cells utilizing $\mathrm{Zn}^{2+}$ fluorophores with mitochondria- and lysosomeselective fluorescent probes will be presented.

\section{References}

1. Truong-Tran AQ, Grosser D, Ruffin RE, Murgi a C, Zalewski PD (2007) Biochem Pharm 66:1459-1468

2. Hashemi M, Ghavami S, Eshraghi M, Booy EP, Los M (2007) Eur J Pharmacol 557:9-19

3. Aoki S, Sakurama K, Matsuo N, Yamada Y, Takasawa R, Tanuma S, Shiro M, Takeda K, Kimura K (2006) Chem Eur J 12:9066-9080 4. Aoki S, Sakurama K, Ohshima R, Matsuo N, Yamada Y, Takasawa R, Tanuma S, Takeda K, Kimura E (2008) Inorg Chem 47:2747-2754

5. Aoki S, Kimura E (2001) Biometals 14:191-204

6. Thompson RB (2005) Curr Opin Chem Biol 7:526-532

7. Kikuchi K, Komatsu K, Nagano T (2006) Curr Opin Chem Biol 8:12-191

8. Kimura E, Aoki S, Kikuta E, Koike T (2003) Proc Natl Acad Sci USA 100:3731-3736

9. Kimura E, Takasawa R, Tanuma S, Aoki S (2004) Science STKE pl 7

\section{P069}

\section{Interaction of V3 loop fragments of HIV-1}

\section{with multivalent anionic Porphyrins}

Kenji Watanabe, Shigeru Negi, Yukio Sugiura, and Koji Kano

${ }^{1}$ Department of Molecular Chemistry and Biochemistry,

Doshisha University, Kyotanabe, Kyoto 610-0321, Japan.

kkano@mail.doshisha.ac.jp

The cyclic peptides, V3Ba-L and V3IIIB, whose amino acid sequences correspond to those of the V3 loop regions of the gp120 exterior proteins of the HIV-1Ba-L and HIV-1IIIB strains, respectively, were synthesized to study the interactions of these V3 loop fragments with multivalent anionic porphyrins and their iron complexes. As the anionic porphyrins, tetrakis(3,5-dicarboxylatophenyl) porphyrin (OCPP), tetrakis[4-(3,5-dicarboxylatophenylmethoxy) phenyl]porphyrin (P2), and their ferric complexes were used. Both V3 peptides formed stable complexes of these multivalent porphyrins. UV-vis spectroscopic titrations with varying the ionic strength of the medium suggest that electrostatic interactions between the cationic V3 peptides and anionic OCPP as the major driving force for complexation, while weaker effect of the ionic strength was observed for the $\mathrm{V} 3 \mathrm{Ba}-\mathrm{L} / \mathrm{Fe}$ (III)OCPP system. The results suggest the coordination of amino acid residue(s) to the iron center of Fe(III)OCPP. EPR and $1 \mathrm{H}$ NMR spectra of the complex of V3Ba-L and FeOCPP showed that the histidine (His) residues at the 13- and 34-positions of the V3Ba-L peptide coordinate to Fe(III)OCPP. The V3IIIB peptide has a His residue adjacent to the $\mathrm{N}$ terminal. The binding constant for the complex of V3IIIB and Fe(III)OCPP was smaller than that for the V3IIIB/ OCPP complex. The thermodynamic parameters obtained from the isothermal titration calorimetry (ITC) suggest that van der Waals interactions between the porphyrin cores and the peptide are also important binding force besides electrostatic and coordination interactions. Since P2 and Fe(III)P2 formed self-aggregates in aqueous solution even at low concentration, detail information on the interaction with the V3 peptides and P2 and Fe(III)P2 was not obtained. However, spectroscopic data indicate the stronger interactions of $\mathrm{P} 2$ and $\mathrm{Fe}(\mathrm{III}) \mathrm{P} 2$ with the V3 peptides compared with OCPP and Fe(III)OCPP.

\section{P070}

\section{Metal ion chelators in the therapy for Alzheimer's disease}

Tamás Kiss, A. Lakatos, É. Zsigó

Department of Inorganic and Analytical Chemistry,

University of Szeged, Dóm tér 7, 6720 Szeged, Hungary

Several studies have shown dyshomeostasis of metal ions, such as $\mathrm{Zn}(\mathrm{II}), \mathrm{Cu}(\mathrm{II})$ and $\mathrm{Fe}(\mathrm{III})$ in the brain of $\mathrm{AD}$ patients. Thus, the role of metal ions in the neurodegenerative processes (for example plaque formation) of $\mathrm{AD}$ became important. Accordingly, the reduction of the aberrant metal-protein interactions by metal-protein attenuating compounds (MPAC), which are molecules able to chelate metal ions, is a possible therapeutic way for $\mathrm{AD}$.<smiles>CNCc1ccccn1</smiles>

DMAP<smiles>NCc1ccccn1</smiles>

$\mathrm{H}$<smiles>NCCNCc1ccccn1</smiles>

ENDIP
Two pyridine derivatives, DMAP and ENDIP, have been synthesised for a possible use as metal chelators in the therapy of Alzheimer's disease. Their complex formation with $\mathrm{Cu}(\mathrm{II})$ and $\mathrm{Zn}$ (II) were characterized in detail. Fluorescence spectroscopy and dynamic light scattering measurements proved that ENDIP effectively competes with $\mathrm{A} \beta$ for both $\mathrm{Cu}$ (II) and $\mathrm{Zn}$ (II) and thus is able to prevent the metal ion-induced amyloid aggregation and to resolubilise amyloid precipitates. 


\section{P072}

\section{Are there any palladium(II) complexes with antitumor} activity?

Franz L. Wimmer

Department of Chemistry, Universiti Brunei Darussalam,

Gadong 1410, Brunei Darussalam. fwimmer@fos.ubd.edu.bn

Cisplatin ( cis- $\left.\left[\mathrm{Pt}\left(\mathrm{NH}_{3}\right)_{2} \mathrm{Cl}_{2}\right]\right)$ displays potent activity against certain tumor lines. The question naturally arises - are platinum complexes unique or is it possible to prepare complexes of other transition metals with similar/better activity?

In the nickel triad, the chemistry of palladium and platinum are similar, e.g. both form square-planar metal(II) complexes. One major difference between platinum and its nearest neighbor is that palladium(II) complexes are significantly more labile than their platinum analogues. At the same time, the general requirements for antitumor activity in a $\mathrm{Pt}(\mathrm{II})$ complex are:

A pair of cis leaving groups with moderate lability

Two cis-amine ligands (either $\mathrm{NH}_{3}$ or a primary amine)

This paper examines two questions:

Do direct Pd(II) analogues of active Pt(II) compounds show any antitumor activity?

Is it possible to prepare active $\mathrm{Pd}(\mathrm{II})$ complexes by modulating the lability of the leaving group?

Both monodentate and chelating amines were used for the nonleaving groups.

\section{P073}

\section{Small molecules in Alzheimer's disease}

Sarmad S. Hindo, Allana M. Mancino, Mi Hee Lim*

Department of Chemistry, Life Sciences Institute,

University of Michigan, Ann Arbor 48109-2216, USA.

mhlim@umich.edu

Alzheimer's disease is the common form of dementia in elderly humans. The Alzheimer's hallmarks are the extracellular accumulation of amyloid-beta deposits and the intraneuronal formation of neurofibriallary tangles upon hyperphosphorylation of tau. It has been suggested that abnormal metal homeostasis in Alzheimer's brains triggers the aggregation of amyoloid-beta and tau, leading to Alzheimer's disease. Even though some studies have shown involvement of metal ions in Alzheimer's pathology, it is still unclear. Here, we present more details in metal-induced formation of amyloid plaques as well as interactions of metal-bound amyloid aggregates with small molecules.

\section{P074}

\section{Chemistry of arsenic relevant to environment} and biological systems Hung-Nien Chen ${ }^{1}$, Hsin-Hsuan $\mathrm{Wu}^{2}$, Hua-Fen Hsu* Department of Chemistry, National Cheng Kung University, Tainan 886-6-2757575, Taiwan.13697417@ mail.ncku.edu.tw

Drinking water polluted by arsenic has caused severe health risk in many areas. Arsenic poisoning possibly results in hyperkeratosis, skin lesions, and cancer of the skin, lung, bladder, and kidney. To elucidate toxicity effect of arsenic in molecular basis, it is essential to understand fundamental chemistry of arsenic interacting with biological- and environmental- related molecules. We are aiming on understanding physical and chemical properties of arsenic species interacting with humic substances and related organic compounds by various spectroscopic methods and techniques. We have been exploring the chemistry of As(III) starting material reacting with ligands, containing functional groups of humic acids. On the other hand, the most observations in mammalian toxicology is that a lethal dose of selenium can be overcome by a lethal dose of arsenic. Some researchers discovered glutathione (GSH) in vivo can form an As-Se complexes, which can be excreted from the bile. Against this background, we are prompted to study the chemistry of arsenic thiolate complexes reacting with selenium species.

\section{References}

1. Mead MN (2005) Environ Health Perspect 113:A378-A386

2. Hughes $\operatorname{MF}(2002)$ Toxicol Lett 133:1-16

3. Aletras V, Karaliota A, Kamariotaki M, Hatzipanayioti D,

Hadjiliadis N (2001) Inorganica Chim Acta 312:151-162

4. Gailer J, George GN, Pickering IJ, Prince RC, Ringwald SC, Pemberton JE, Glass RS, Younis HS, DeYoung DW, Aposhian HV (2000) J Am Chem Soc 122:637-4639

\section{P075}

Solution behavior and bimolecular interactions of two cytotoxic trans-platinum (II) complexes bearing aliphatic amine ligands

Leticia Cubo ${ }^{1}$, Angela Casini ${ }^{2,4}$, Chiara Gabbiani ${ }^{2}$, Guido Mastrobuoni $^{3}$, Luigi Messori ${ }^{2}$, Jesús Jiménez-Barbero ${ }^{5}$, Carmen Navarro-Ranninger ${ }^{1}$, Adoración G. Quiroga*1

${ }^{1}$ Department of Inorganic Chemistry, Universidad Autónoma de Madrid, 28045 Madrid, Spain.

${ }^{2}$ Dipartimento di Chimica Università di Firenze, Sesto Fiorentino, Italy.

${ }^{3}$ Mass Spectrometry Centre (CISM), Università di Firenze, Sesto Fiorentino, Italy.

${ }^{4}$ Institut des Sciences et Ingénierie Chimiques (EPFL), 1015 Lausanne, Switzerland.

${ }^{5}$ Centro de Investigaciones Biológicas, CIB-CSIC, 28040 Madrid, Spain. adoracion.gomez@uam.es

The trans platinum complexes with aliphatic amines selected for this presentation represent one of the non-classic trans platinum complexes type mentioned as potential drugs over the last decade. In particular t$\mathrm{PtCl}_{2}(\mathrm{dma})(\mathrm{ma})$ where dma stands for dimethylamine and ma for methylamine has been recently reported and showed higher cytotoxic activity possibly caused by the steric effects of its ligands. The solution behavior in phosphate buffers and water solution was studied under a variety of conditions. Later on, the reactivity of the these trans platinum complexes with horse heart cytochrome $\mathrm{c}$ was analyzed by mass spectrometry and $\left.2 \mathrm{D}{ }^{1} \mathrm{H},{ }^{15} \mathrm{~N}\right],\left[{ }^{1} \mathrm{H},{ }^{13} \mathrm{C}\right] \mathrm{HSQC}$ and $\left[{ }^{1} \mathrm{H},{ }^{1} \mathrm{H}\right]$ NOESY NMR experiments. The implications of the obtained results for the mechanism of action of trans aliphatic amines platinum complexes are thoroughly discussed.

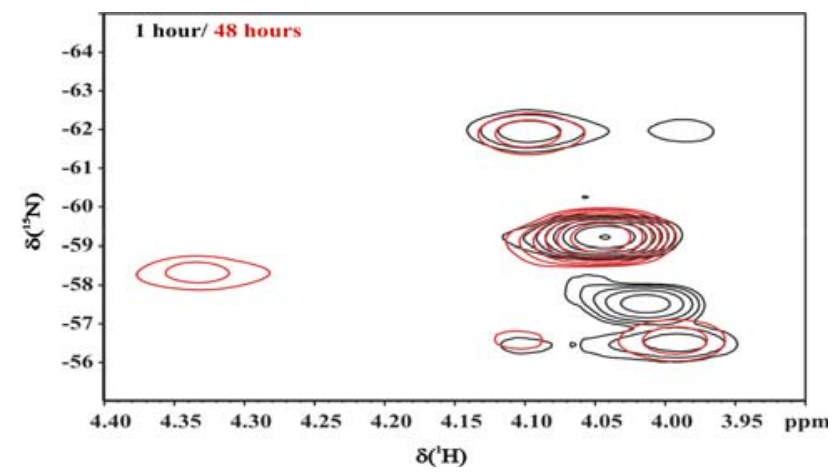




\section{References}

1. Timerbaev AR, Hartinger CG, Aleksenko SS, Keppler BK (2006) Chem Rev 106:2224-2248

2. Cubo L, Quiroga AG, Zhang J, Thomas DS, Carnero A, NavarroRanninger C, Berners-Price SJ (2009) Dalton Trans. doi:10.1039/ b819301k (Featured on the journal front cover)

3. Casini A, Gabbiani C, Mastrobuoni G, Pellicani RZ, Intini FP, Arnesano F, Natile G, Moneti G, Francese S, Messori L (2007) Biochemistry 46:12220-12230

\section{P076}

\section{Investigation into the behavior of cis and trans amine} platinum complexes in aqueous solution by $2 \mathrm{D}\left[{ }^{1} \mathrm{H},{ }^{15} \mathrm{~N}\right]$

\section{HSQC NMR}

Leticia Cubo' ${ }^{1}$, Adoración G. Quiroga', Junyong Zhang ${ }^{2}$, Donald S. Thomas ${ }^{2}$, Amancio Carnero ${ }^{3}$,

Carmen Navarro-Ranninger ${ }^{1}$ and Susan J. Berners-Price ${ }^{2}$

${ }^{1}$ Departamento de Química Inorgánica, Universidad Autónoma de Madrid, Madrid, Spain.

${ }^{2}$ School of Biomedical, Biomolecular \& Chemical Sciences,

The University of Western Australia, Perth, Australia.

${ }^{3}$ CNIO, Madrid, Spain. leticia.cubo@uam.es

The ${ }^{15} \mathrm{~N}$-labeled complexes cis-[ $\left.\mathrm{PtCl}_{2}\left({ }^{15} \mathrm{~N} \text {-dma }\right)_{2}\right]$, trans- $\left[\mathrm{PtCl}_{2}\left({ }^{15} \mathrm{~N}\right.\right.$ ipa) $\left({ }^{15} \mathrm{~N}\right.$-ma) $]$, trans-[ $\mathrm{PtCl}_{2}\left({ }^{15} \mathrm{~N}\right.$-dma $)\left({ }^{15} \mathrm{~N}\right.$-ma $\left.)\right]$ and trans- $\left[\mathrm{PtCl}_{2}\right.$ $\left({ }^{15} \mathrm{~N}\right.$-dma) ${ }^{15} \mathrm{~N}$-ipa) $]$ have been prepared and characterized. The aquation of these ${ }^{15} \mathrm{~N}$-labeled complexes in $0.1 \mathrm{M} \mathrm{NaClO}_{4}$ at $298 \mathrm{~K}$ was followed by $2 \mathrm{D}\left[{ }^{1} \mathrm{H},{ }^{15} \mathrm{~N}\right] \mathrm{HSQC}$ NMR spectroscopy. These studies were performed to obtain the rate and equilibrium constants for the first and second aquation steps and also determine the $\mathrm{p} K_{\mathrm{a}}$ values of the aqua ligands in the mono- and diaqua species. The aquation data were analyzed using the model shown in the scheme. Our study allows comparison between the aquation of the cis complex with the related trans dma complexes. Moreover, the influence of the amine ligand on the aquation chemistry of these three trans complexes were investigated. The cytotoxicity was also assessed in the cancer lines SF268, MCF-7 and NCI-H460 for the trans complexes to analyze the role for hydrolysis in the mechanism of antitumor activity.

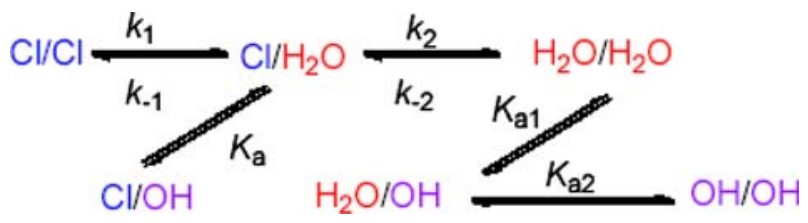

\section{References}

1. Cubo L, Thomas DS, Zhang J, Quiroga AG, Navarro-Ranninger C, Berners-Price SJ (2008) Inorg Chim Acta 362:1022-1026

2. Cubo L, Quiroga AG, Zhang J, Thomas DS, Carnero A, NavarroRanninger C, Berners-Price SJ (2009) Dalton Trans. doi:10.1039/ b819301k (Featured on the journal front cover)

\section{P077}

\section{Platinum(II) and palladium(II) oxalato complexes} involving N6-benzyladenine-based CDK-inhibitors Pavel Štarha, Igor Popa, Zdeněk Trávníček

Department of Inorganic Chemistry, Faculty of Science, Palacky University, Krizkovskeho 10, 77147 Olomouc, Czech Republic. zdenek.travnicek@upol.cz

This work represents a continuation of our systematic research of transition metal complexes with N6-benzyadenine derivatives. It deals with synthesis, characterization and in vitro cytotoxicity study of the platinum(II) and palldium(II) oxalato complexes of the general formula $\left[\mathrm{Pt}(\mathrm{L})_{2}(\mathrm{ox})\right]$ and $\left[\mathrm{Pd}(\mathrm{L})_{2}(\mathrm{ox})\right]$, where $\mathrm{L}$ stands for a molecule of the cyclin-dependent kinase (CDK) inhibitor derived from N6benzyl-9-isopropyladenine moiety. The complexes have been synthesized by a reaction of $\mathrm{K}_{2}\left[\mathrm{M}(\mathrm{ox})_{2}\right] \cdot 2 \mathrm{H}_{2} \mathrm{O}(\mathrm{M}=\mathrm{Pt}$ or Pd) with two molar equivalents of the appropriate $\mathrm{L}$ organic compounds. The prepared complexes have been fully characterized by varied methods including multinuclear NMR spectroscopy and single-crystal X-ray analysis. The geometry of complexes is square-planar with tetracoordinated central transition metal ion and $\mathrm{PtN}_{2} \mathrm{O}_{2} / \mathrm{PdN}_{2} \mathrm{O}_{2}$ donor set. Two $\mathrm{L}$ molecules are coordinated through $\mathrm{N} 7$ atoms of their purine moieties. Some of the complexes have shown significant in vitro cytotoxic properties against selected human cancer cell lines (MCF-7, K-562, HOS). In some cases, the determined $\mathrm{IC}_{50}$ values have been found even lower compared to commercially used platinum-based anticancer drugs such as cisplatin, carboplatin and oxaliplatin.

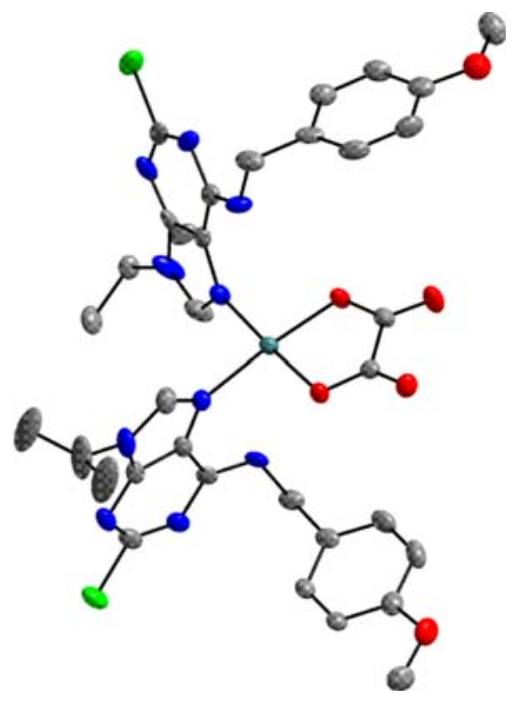

P078

Photocytotoxicity of ternary iron(III) complex of dipyridophenazine: a potent photodynamic therapeutic agent

Sounik Saha ${ }^{1}$, Ritankar Majumdar ${ }^{2}$, Mithun Roy ${ }^{1}$, Rajan R. Dighe ${ }^{2}$, Akhil R. Chakravarty ${ }^{1 *}$

${ }^{1}$ Department of Inorganic and Physical Chemistry,

${ }^{2}$ Department of Molecular Reproduction, Development and Genetics, Indian Institute of Science, Bangalore 560 012, India.

arc@ipc.iisc.ernet.in

Photodynamic therapy is an emerging non-invasive treatment modality for cancer. It requires the simultaneous presence of a photosensitizing drug and light to induce cytotoxic effect. The currently used drug Photofrin ${ }^{\circledR}$ suffers from high skin sensitivity and hepatoxicity. The $3 \mathrm{~d}$ metal complexes with low energy chargetransfer and/or $\mathrm{d}-\mathrm{d}$ band provide an excellent platform for designing metal-based PDT agents. We have synthesized and structurally characterized ternary high-spin iron(III) complexes with a tetradentate phenolate-based ligand and phenanthroline bases, viz. 1,10-phenanthroline, dipyridoquinoxaline and dipyridophenazine. The complexes are avid binders to calf thymus DNA and bovine serum albumin (BSA) protein. The complexes on photo-excitation of the phenolate-to-Fe(III) charge-transfer band with red light show significant cleavage of supercoiled pUC19 DNA but not of BSA protein. The dipyridophenazine complex, which is non-toxic in 
dark, was found to induce cytotoxicity upon excitation with UV-A or visible light in $\mathrm{HeLa}$ and $\mathrm{HaCaT}$ cells. Cytotoxic hydroxyl radicals were found to form from EPR spectroscopy and mechanistic studies.

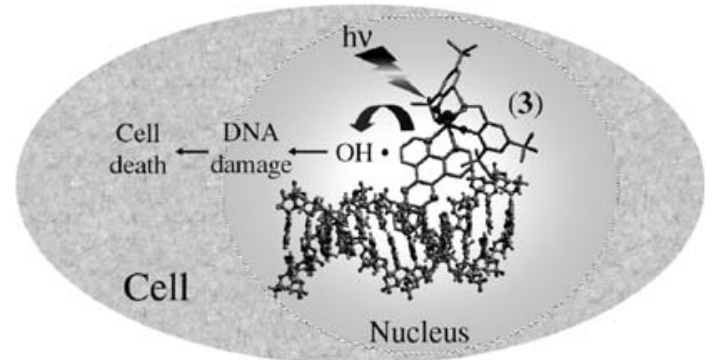

\section{P079}

\section{Cytotoxic activities of Ru/nitrosyl/diphosphine}

complexes

Camilla C. Golfeto ${ }^{1}$, Marilia I. Frazão Barbosa ${ }^{1}$

Gustavo Von Poelhsitz ${ }^{2}$, Javier A. Ellena ${ }^{3}$,

Eduardo E. Castellano ${ }^{3}$, Alzir A. Batista ${ }^{1}$ *

${ }^{1}$ Departamento de Química, Universidade Federal de São Carlos, São Carlos (SP), Brazil.

${ }^{2}$ Departamento de Química, Universidade Federal de Goiás, Campus Catalão, Catalão, (GO), Brazil.

${ }^{3}$ Instituto de Física de São Carlos, USP, São Carlos (SP), Brazil. daab@power.ufscar.br

Our research group has been interested in the synthesis of ruthenium complexes containing phosphines as ligands in order to evaluate their cytotoxic activities against tumor cells lines [1-2]. In this work we will present some results involving experiments with nitrosyl/ruthenium/diphosphine complexes and MDA-MB-231 cell line. The $\mathrm{IC}_{50}$ values for the MDA-MB-231 cell line of the nytrosil/ruthenium complexes, in DMSO solutions, are between 7.1 and $21.0 \mu \mathrm{M}$, while the cisplatin, in the same experimental conditions shows its $\mathrm{IC}_{50}$ as $63 \pm 5 \mu \mathrm{M}$. Some results with carbonyl/ruthenium/diphosphine complexes will be also shown.

\section{References}

1. do Nascimento Fabio B, Von Poelhsitz Gustavo, Pavan Fernando R, Sato Daisy N, Leite Clarice QF, Selistre-de-Araujo Heloisa S, Ellena Javier, Castellano Eduardo E, Deflon Victor M, Batista Alzir A (2008) J Inorg Biochem 102(9):1783-1789

2. Graminha Angelica E, Rodrigues Claudia, Batista Alzir A, Teixeira Leticia R, Fagundes Elaine S, Beraldo Heloisa (2008) Spectrochim Acta A Mol Biomol Spectrosc 69A(4):1073-1076

Acknowledgements: FAPESP, CAPES and CNPq for financial support.

\section{P080}

\section{Spheroid penetration and accumulation of platinum anti-tumour complexes}

Jenny Zhang, Nicole Bryce, Renee Whan, Trevor Hambley

The School of Chemistry, The University of Sydney, Sydney,

Australia.j.zhang@chem.usyd.edu.au

The inability of many anti-tumour agents to penetrate into tumours effectively has been well documented and contribute to tumour regrowth and clinical resistance [1,2]. This poor penetration is mostly attributed to the limited ability of the drug molecules to diffuse more than 3-4 cell diameters from the blood vessels, as well as the abnormal vasculature, giving rise to conditions such as hypoxia and acidosis in the tumour cores $[3,4]$.
We have synthesized several Pt(II)-anthraquinone complexes that possess characteristics such as high lipophilicity, positive charges, and low reactivities, all of which have been suggested to be important determinants for tumour penetration and selectivity [5, 6]. The behaviour of these drugs has already been studied extensively on the cellular level. Recently, we have used confocal microscopy and GFAAS to measure and compare the degree of penetration and the platinum accumulation of these complexes inside spheroids, which are three-dimensional multicelullar tumour models.

From these studies, we have found that the positively charged complex with the inert platinum centre showed a greater proportion of spheroid penetration compared with its neutral, labile analogue and the free anthraquinone ligand. This trend was observed consistently across three different cell lines. Additionally platinum accumulation studies revealed a significant difference in trends obtained from monolayer cellular studies and spheroids studies, suggesting that the tradeoff between cellular uptake and tumour penetration is an important consideration when designing drugs.

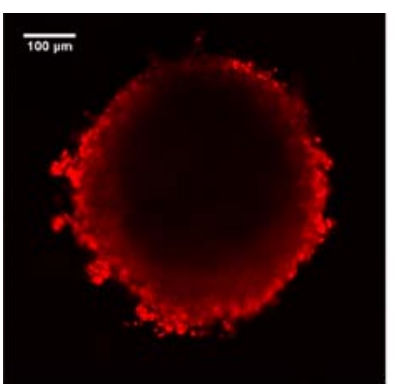

Pt1C3 treated spheroid

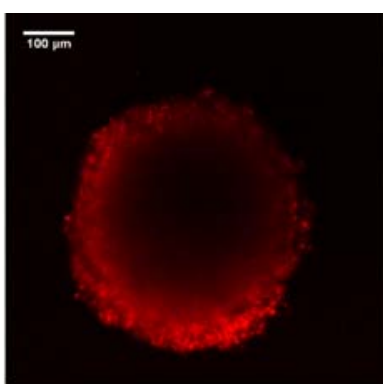

Ptdien $1 \mathrm{C} 3^{2+}$ treated spheroid

\section{References}

1. Tunggal JK, Cowan DSM, Shaikh H, Tannock IF (1999) Clin Cancer Res 5:1583-1586

2. Durand RE (1989) J Natl Cancer Inst 81:146-152

3. Primeau AJ, Rendon A, Hedley D, Lilge L, Tannock IF (2005) Clin Cancer Res 11:8782-8788

4. Minchinton AI, Tannock IF (2006) Nat Rev Cancer 6:583-592

5. Kerr DJ, Wheldon TE, Hydns S, Kaye SB (1988) Xenobiotica 18:641-648

6. Nederman T, Carlsson J, Kuoppa K (1988) Cancer Chemother Pharmacol 22:21-25

\section{P081}

Metal-based paullones as potential antitumour drugs Vladimir B. Arion, Michael A. Jakupec, Bernhard K. Keppler Institute of Inorganic Chemistry of the University of Vienna, Waehringerstr. 42,1090 Vienna, Austria.vladimir.arion@univie.ac.at Dihydroindolo[3,2-c]benzazepines or paullones (Fig. 1) are known as potent inhibitors of cyclin-dependent kinases (CDKs) which control cell-cycle progression and often show increased activity in cancer cells due to upregulated cyclin-expression, what makes them interesting candidates for the development as antitumour drugs. One of the limitations encountered on this way is their low aqueous solubility and bioavailability. We show that these intrinsic limitations can be overcome by creation of metal binding sites at the periphery of molecule backbone and complexation with metal ions. We report herein on the synthesis, structural and spectroscopic characterisation of a number of paullones with different location of the metal binding site, and their metal complexes. This enabled the study of the effect of metallation on the antiproliferative activity of the prepared compounds in three human cancer cell lines $\mathrm{CH} 1$ (ovary carcinoma), 
A549 (lung carcinoma) and SW480 (colon carcinoma) and on the cell-cycle distribution. Our data suggest that metal-based paullones are good candidates indeed for further development as potential antitumour drugs.

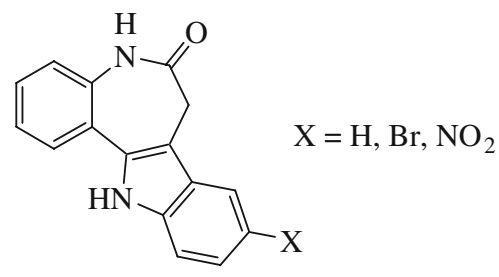

Fig. 1 Structure of paullone derivatives

\section{P082}

\section{The power of prions: towards a role for PrP}

\section{in the synapse}

Alison C. Badrick ${ }^{1}$, Christopher E. Jones ${ }^{1,2}$

${ }^{1}$ Centre for Metals in Biology, School of Chemistry and Molecular Biosciences,

${ }^{2}$ The Queensland Brain Institute, The University of Queensland, St Lucia, Queensland, 4072, Australia. a.badrick@uq.edu.au

The prion protein $(\mathrm{PrP})$ is a highly conserved cuproprotein found on the surface of cells, and is especially abundant on the presynaptic membrane in the nervous system. This discovery has led to the suggestion that the protein plays an important role in the synapse. The interplay between PrP and copper has been investigated by numerous groups. Up to six $\mathrm{Cu}^{2+}$ ions have been shown to bind in the unstructured $\mathrm{N}$-terminal region of the protein. Various functions have been postulated for the protein, including the ability to act as an antioxidant, which has a requirement for the copper to redox-cycle between the +1 and +2 oxidation states.

Using various synthetic PrP peptides corresponding to the known $\mathrm{Cu}^{2+}$-binding regions, we have identified a $(\mathrm{His})_{2}(\mathrm{Met})_{2}$ high-affinity $\mathrm{Cu}^{+}$-binding site within the so-called 'fifth $\mathrm{Cu}^{2+}$-binding site'. This coordination is similar in structure and affinity to periplasmic bacterial $\mathrm{Cu}^{+}$transporters. Functional implications for the protein involving versatile redox properties will be discussed.
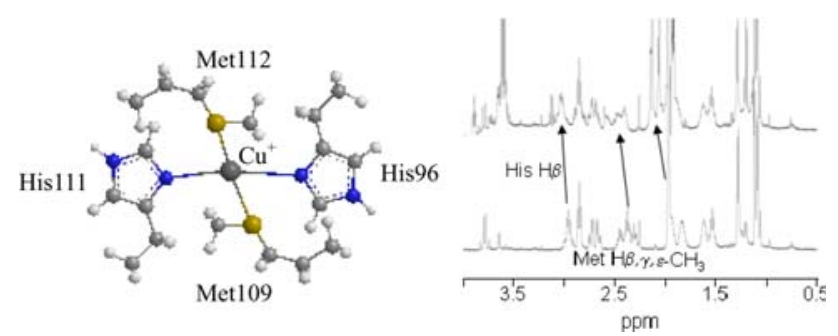

P083

\section{PAMAM dendrimers as delivery vehicles for platinum anticancer drugs}

Gordon J. Kirkpatrick, Oliver B. Sutcliffe,

David J. Flint, Nial J. Wheate*

Strathclyde Institute of Pharmacy and Biomedical Sciences,

University of Strathclyde, John Arbuthnott Building, 27 Taylor Street, Glasgow G4 0NR, UK. Gordon.Kirkpatrick@strath.ac.uk

The use of platinum anticancer agents such as cisplatin, carboplatin and oxaliplatin is limited due to adverse side effects and acquired or intrinsic resistance of the cancer cells to the drug [1]. Dendrimers are well defined hyperbranched polymers with high end group functionality and are readily modified into biocompatible compounds with low cytotoxicity and high biocompatibility [2]. Full generation PAMAM dendrimers have amine surface groups and half generation dendrimers have carboxylate surface groups. We were interested in using functionalised PAMAM dendrimers as a delivery vehicle for the platinum anticancer drugs cisplatin and oxaliplatin. Recently we have prepared cisplatin conjugated PAMAM dendrimers (generation 3.56.5) and examined them for: platinum content and dendrimer size, DNA binding rate, drug release rate, in vitro cytotoxicity in the A2780 and A2780cis cell lines.

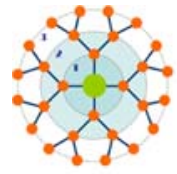

Dendrimer<smiles>N[PH](N)(Cl)Cl</smiles>

Cisplatin<smiles>C=C1OC2(CNC3CCCCC3N2)OC1=O</smiles>

Oxaliplatin
References

1. Kelland L (2007) Nat Rev Cancer 7:573-584

2. Wolinsky JB, Grinstaff MW (2008) Adv Drug Del Rev 60:10371055

\section{P084}

\section{Ruthenium NO-donors as a chemotherapeutic candidates for American trypanosomiasis} Luiz G. F. Lopes ${ }^{1}$, Francisco O. N. da Silva ${ }^{1}$, Adriano D. Andricopulo $^{2}$, João S. Silva ${ }^{3}$, Glaucius Oliva ${ }^{2}$, Jean J. N. Silva ${ }^{2 *}$

${ }^{1}$ Departamento de Química Orgânica e Inorgânica, UFC, Brazil.

${ }^{2}$ Instituto de Física de São Carlos, USP, Brazil.

${ }^{3}$ Departamento de Bioquímica e Imunologia, FMRP, Brazil An intensive effort has been directed toward finding alternative drugs for treatment of American trypanosomiasis or Chagas' disease, caused by Trypanosoma cruzi, and prophylaxis of blood in endemic and non-endemic areas. Lead discovery is currently a key bottleneck in the Chagas' disease pipeline for novel drugs. It has been demonstrated that ruthenium NO-donors is able to lyse $T$. cruzi in vitro and in vivo by a mechanism NO-dependent. Herein, we show that the ruthenium nytrosil complexes of the type $c i s-\left[\mathrm{Ru}(\mathrm{NO})(\mathrm{bpy})_{2} \mathrm{~L}\right]\left(\mathrm{PF}_{6}\right)_{\mathrm{n}}$ where $\mathrm{L}=$ sulfite ion, $\mathrm{SO}_{3}^{2-}(\mathrm{A})$, imidazole, imN (B), and 1-methylimidazole, miN (C) are potent inhibitors of GAPDH from T. cruzi and exhibit promising in vitro and in vivo trypanocidal activities. The enzymatic assays were was monitored by the biochemical reduction of $\mathrm{NAD}^{+}$to $\mathrm{NADH}$ at $340 \mathrm{~nm}$ for 8 min using a Cary $100 \mathrm{Bio} \mathrm{UV/}$ $\mathrm{V}$ equipped with a Peltier-thermostatted multicell changer and a temperature controller. The values $\left(\mathrm{IC}_{50}^{\mathrm{GAPDH}}\right)$ represent means of at least three individual experiments, and were estimated from the collected data employing the Sigma-Plot enzyme kinetics module. The in vitro and in vivo experiments were performed according to a well established protocol using a partially drug-resistance (Y) strain of T. cruzi. The ruthenium NO-donors (A, B, and $\mathrm{C}$ ) showed high in vitro trypanocidal activity with $\mathrm{EC}_{50}$ values range from 52 to $121 \mu \mathrm{M}$. In a in vivo model, the complexes A and B showed 80 and $60 \%$ of protection against death whereas the standard drug benznidazole no exhibited any protection at same doses $(100 \mathrm{nmol} / \mathrm{kg}$ per day). Furthermore, these complexes were able to inhibit the GAPDH by $\mathrm{S}$-nitrosylation mechanism with $\mathrm{IC}_{50}^{\mathrm{GAPDH}}$ values in low micromolar concentrations.

The ability to achieve this level of potency in animal models with these new inorganic inhibitors of $T$. cruzi GAPDH is remarkable and likely to have a significant impact on the future design of chemotherapeutic candidates against Chagas' disease. 


\section{P085}

Inhibition of protein splicing by metal complexes Liyun Zhang, Yangzhong Liu

Department of Chemistry, University of Science and Technology of China, Hefei, Anhui, 230026, China. liuyz@ustc.edu.cn

Self-catalytic protein splicing is a post translational process in which the intervening protein, intein, is cleaved from the precursor proteins with the concomitant ligation of flanking sequences [1]. It was discovered recently that recA was one of the proteins associated with M. tuberculosis drug resistance. However, the recA protein in M. tuberculosis is synthesized in an inactive form with an intein insertion. Inhibition of protein splicing could prevent the maturity of recA in M. tuberculosis.

The initial in vitro screening was performed on a green fluorescent protein (GFP) with recA intein insertion. The fluorescence of GFP protein will recover after the spontaneous protein splicing. Inhibitors have been screened from over 100 complexes from seven metal compounds $(\mathrm{Cu}, \mathrm{Co}, \mathrm{Ni}, \mathrm{Zn}, \mathrm{Au}, \mathrm{Pt}$, and $\mathrm{Ru})$ with different ligands. Figure shows a representative result of inhibition assay, giving an $\mathrm{IC}_{50}$ value of $2.5 \mu \mathrm{M}$. The second inhibition assay was carried out on $E$ coli, which showed the in vivo activity of inhibitors. The inhibition of M. tuberculosis cell growing was performed on H37Rv cells, which demonstrated that the complex could completely inhibit cell growing at $40 \mu \mathrm{M}$. This minimal inhibitory concentrations (MIC) value is in the similar range of antimycobacterial agents, ethambutol and rifampicin, which are currently in clinical use for the treatment of TB.
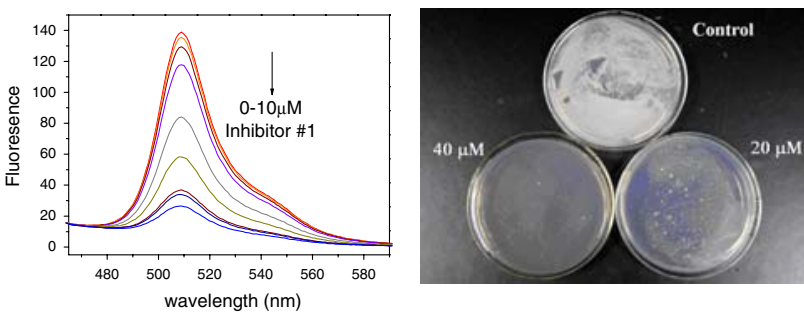

Reference

1. Muralidharan V, Muir TW (2006) Nat Methods 3:429-438

\section{P086}

\section{Speciation analysis in preclinical metallodrug} development

Stephan Hann ${ }^{1}$, Katharina Boeck ${ }^{1}$, Thomas Falta ${ }^{1}$, Petra Heffeter ${ }^{2}$, Walter Berger ${ }^{2}$, Bernhard Keppler ${ }^{3}$, Gunda Koellensperger ${ }^{1}$

${ }^{1}$ Department of Chemistry, University of Natural Resources and Applied Life Sciences, BOKU Vienna, Austria.

2 Department of Medicine I, Institute of Cancer Research, Medical University Vienna, Austria.

${ }^{3}$ Institute of Inorganic Chemistry, University of Vienna, Austria. Gunda.Koellensperger@boku.ac.at

We will present novel analytical tools based on the combination of chromatographic separations with inorganic mass spectrometry. The method development concerned (1) quantification of metallodrug and corresponding hydrolysis products or metabolites and (2) the targeted quantification of metallodrug-protein complexes, both in cell models and in vivo.

We will present our latest results concerning the intracellular fate of cisplatin and sodium trans-[tetrachlorobis( $1 \mathrm{H}$-indazole)ruthenate(III)]
(KP1339). We could show that only a minor fraction of cisplatin was protein bound in the cytoplasm, whereas KP1339 showed prominent protein binding. The free drug cisplatin, monoaqua cisplatin and diaqua cisplatin were quantified in the cytoplasm of different cell models. Moreover, KP1339 was investigated in animal models. In the past we were able to show that indazolium trans-[tetrachlorobis( $1 H$-indazole) ruthenate(III)] (KP1019) was bound to human serum albumin in vivo (clinical trial phase 1) by the use of two-dimensional separations on intact protein level with ICP-MS detection [1]. As a drawback the detection power of the method regarding the transferrin-drug adducts was low and had to be improved for the mouse serum samples.

\section{Reference}

1. Sulyok M, Hann S, Hartinger CG, Keppler BK, Stingeder G, Koellensperger G (2005) J Anal At Spectrom 20:856-863

\section{P087}

\section{Characterization of copper(II) binding to membrane} associated PrP(91-124), part of the putative 'transmembrane' domain of the prion protein

\section{Christopher E. Jones}

Centre for metals in Biology, School of Molecular and Microbial Sciences and The Queensland Brain Institute, The University of Queensland, St Lucia, 4072, Brisbane, Australia.

christopheredward.jones@uq.edu.au

The Prion protein is a cuproprotein involved in neurodegenerative diseases such as Creutzfeldt-Jakob Disease in humans and 'Mad Cow' disease in cattle. The protein is usually tethered to the plasma membrane via a specific anchor, but interaction of the polypeptide with the membrane can also occur. A highly hydrophobic region (residues 106-136) has been shown to span the lipid bilayer, and a model peptide containing part of this sequence, $\operatorname{PrP}(106-126)$ is neurotoxic. Interaction of the PrP polypeptide with membranes is thought to potentially contribute to Prion disease progression and pathogenicity.

An intriguing feature of the hydrophobic domain is the presence of two $\mathrm{Cu}^{2+}$ sites towards the N-terminal region (at His96 and His111). How and if copper affects Prion membrane interactions is unclear, yet modulation of membrane interactions may influence or contribute to pathogenicity. Using a model peptide that incorporates these two sites and part of the hydrophobic domain, $\operatorname{PrP}(91-124)$ we have investigated if membranes alter the interaction of copper with the His96/111 sites. Tryptophan fluorescence and sucrose density gradients show that $\operatorname{PrP}(91-124)$ binds to vesicles composed of anionic lipids and the peptide adopts a largely helical character when bound. Electron Paramagnetic Resonance shows that copper binds to the membrane associated peptide in a manner similar to its coordination to the soluble peptide. Structurally, there is loss of helical character. The bound copper is resistant to abstraction by chelators, potentially because the lipid surface helps shield the ions from solution.

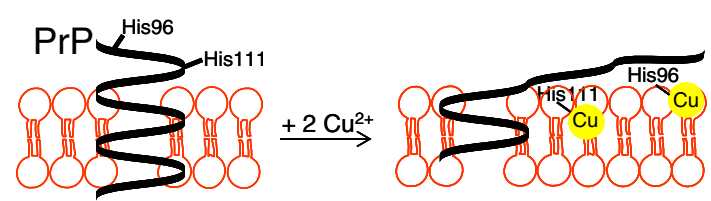

